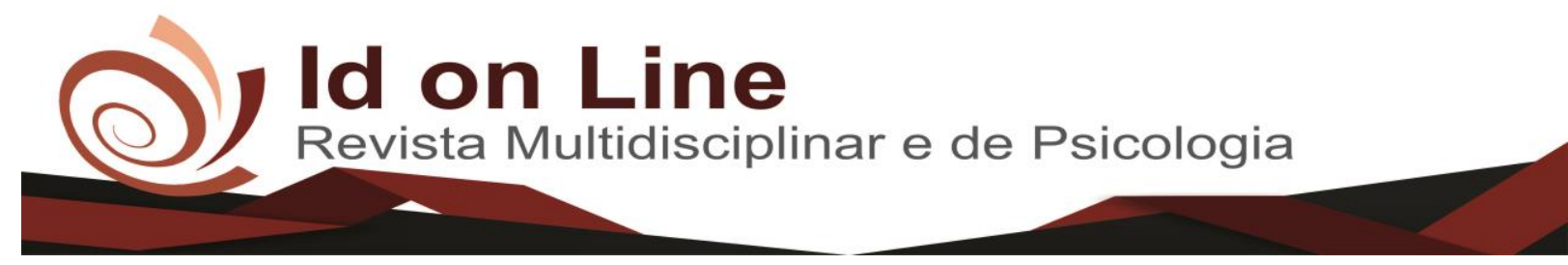

Relato de Experiência

\title{
O "Ser Mãe": Representações Sociais do Papel Materno de Gestantes e Puérperas
}

\author{
Jadne Meder Estrela ${ }^{1}$; Maira da Silva Machado ${ }^{2}$, Amanda Castro ${ }^{3}$
}

\begin{abstract}
Resumo: Esse artigo trata-se de um relato de experiência, que busca descrever a vivência de estágio social de duas acadêmicas de Psicologia no setor da maternidade em um hospital de ensino, visando a reflexão acerca das representações sociais do papel de mãe de mulheres gestantes e/ou puérperas em internação, bem como seus familiares ou acompanhantes, tendo como objetivo desconstruir os estereótipos associados ao papel de mãe. Os diálogos aconteceram através de intervenções psicossociais realizadas semanalmente em quartos coletivos de internas que se voluntariaram para participar. As intervenções duravam em média 20 minutos. Participaram 45 pessoas, incluindo acompanhantes e familiares. Decorrente disso, reunimos falas significativas a respeito do papel materno a partir da realidade subjetiva destas mulheres, mas que também fazem parte do pensamento amplamente difuso na sociedade, como por exemplo o papel secundário da figura paterna e a obrigatoriedade do amor incondicional da mãe.
\end{abstract}

Descritores: Maternidade; Psicologia Social; Representações Sociais.

\section{The "Mother Being": Social Representations of the Maternal Role of Gestants and Woman in Puerperal Period}

\begin{abstract}
This article is about an experience report, which aims to describe the experience of social stage of two psychology students in the maternity sector in a schoolar hospital, seeking to reflect on the social representations of the role of mother of pregnant women and / or postpartum women in hospital, as well as their relatives or companions, with the objective of deconstructing the stereotypes associated with the role of mother. The dialogues took place through weekly psychosocial interventions in collective rooms of inmates who volunteered to participate. The interventions lasted an average of 20 minutes. It was attended by 45 people, including companions and family members. As a result, we have gathered significant statements about the maternal role from the subjective reality of these women, but also are part of the widely diffused thinking in society, such as the secondary role of the father figure and the obligation of the mother's unconditional love.
\end{abstract}

Keywords: Maternity; Social Psychology; Social Representations.

\footnotetext{
${ }^{1}$ Graduanda de Psicologia da Universidade do Extremo Sul Catarinense - UNESC. jadnemederestrela@ gmail.com

${ }^{2}$ Universidade do Extremo Sul Catarinense - UNESCmaiaram2303@gmail.com

${ }^{3}$ Psicóloga. Doutoranda em Psicologia pelo Programa de Pós Graduação da Universidade Federal de Santa Catarina. Docente na Universidade do Extremo Sul Catarinense - UNESC.amandacastrops@ gmail.com
} 


\section{Introdução}

O estágio obrigatório em Psicologia Social propõe a realização de um projeto de sua área de abrangência, incluso na disciplina de ESTÁGIO B - PSICOLOGIA SOCIAL da Universidade do Extremo Sul Catarinense - UNESC. O estágio ocorreu em um hospital de ensino privado em convênio com a rede de atendimento SUS, localizado no extremo sul catarinense, pelo período de cinco meses.

O hospital não somente é um local de enfermidades e sofrimento, embora geralmente as circunstâncias que nos levam à procura do hospital são os processos de adoecimento, mas também de nascimento e felicidade acerca da chegada de um bebê. Em virtude disso, a ala hospitalar da maternidade constitui-se um campo rico para a Psicologia Social, visto que possibilita a construção de estratégias para o enfrentamento e resolução de situações enfrentadas pelas mulheres dentro e fora do hospital, permitindo uma escuta ativa relacionada à maternagem. A maternidade, descrita como uma experiência única pela maioria das mulheres, vem acompanhada de uma série de mudanças físicas e psíquicas na mulher. As mudanças corporais que ocorrem nas mulheres são mais facilmente observáveis e vêm acompanhadas da liberação desenfreada de hormônios. No entanto, é preciso observar igualmente as transformações psíquicas decorridas desse processo, afinal, ao engravidar a mulher também precisa configurar um espaço psíquico para o "tornar-se mãe", e para as expectativas em relação ao seu companheiro como "pai” (FOLINO, 2014).

Nesse sentido, ressaltamos também que partindo da perspectiva que a mulher algum dia venha a se tornar mãe, ao longo dos anos amplificou-se o pensamento de que a maternidade era inata, biológica e instintiva à mulher, independente de outros fatores, como a cultura e a condição socioeconômica. Assim, ainda há o retrato de que toda mulher deve experimentar a maternidade para alcançar a completude, para experimentar o amor incondicional (AZEVEDO, 2017).

Porém, o que também se mostra presente é o sofrimento a essa condição de possuidora de um amor incondicional. A gravidez é um estágio de transição que pode causar instabilidade emocional temporária nas mulheres. O papel familiar e social da mulher é reorganizado, e ela começa a passar por adaptações, já que além de mulher e filha, ela também se tornará mãe e educadora (TOURINHO, 2006). 
Na maior parte dos casos, o período gravídico estimula o desenvolvimento de inúmeras expectativas dos pais em relação à criança, que vêm acompanhadas de desejos, sentimentos, e também ansiedade em relação ao nascimento. A maternidade é idealizada, de certa forma, e essa idealização geralmente vai se diluindo à medida que alguns desafios surgem ao longo do caminho, testando as supostas habilidades e competências das mulheres no papel de mãe (LEAL, 2013).

O papel materno, no entanto, é composto por inúmeros estereótipos. O estereótipo pode ser entendido como uma forma de reprodução e confirmação de representações provindas do senso comum e de ideias já estabelecidas que correspondam ou não a alguém ou algo, formando representações sociais a partir de repetições de fácil entendimento para explicar situações incomuns à rotina de quem as enuncia (COZER, 2013).

As representações sociais e os estereótipos estão relacionados às imagens construídas pela sociedade de objetos sociais, grupos e pessoas. As representações sociais constituem a forma de explicar e interpretar o mundo em que as pessoas vivem, e a maneira de descrever as pessoas e objetos sociais constitui os estereótipos (KOELZER et al, 2016).

Em relação ao estereótipo sobre a maternidade, é possível perceber que esta ainda é descrita de forma muito romanceada. Ser mãe é associado a aspectos idealizados, tais como: sacrifício, amor incondicional e disponibilidade completa. Entretanto, essas concepções contrapõem-se à experiência real do papel materno (TRAVASSOS-RODRIGUEZ; FÉRESCARNEIRO, 2013).

A maternidade traz consigo certa ambivalência (AZEVEDO, 2017), englobando o ideal e o real de ser mãe. É preciso romper com o modelo materno ideal imposto pela cultura vigente, que exclui a possibilidade da coexistência de sentimentos ambivalentes na relação da mãe com o bebê. Ser mãe implica em momentos de alegria, mas igualmente em momentos de dor, tristeza e muitas vezes arrependimento. Desde a revolução feminista e a inserção da mulher no mercado de trabalho, a mesma vem, gradativamente, aprendendo a conviver com a maternidade associada à culpa. O estereótipo de mãe perfeita e profissional bem-sucedida se traduz em sobrecarga emocional e adoecimento mental (TRAVASSOS-RODRIGUEZ; FÉRESCARNEIRO, 2013).

Nesse sentido, é importante reconhecer as possíveis dificuldades e o sofrimento que a maternidade pode trazer para algumas mulheres, embora também seja uma fonte de gratificações para outras (SCHULTE, 2016). 
Buscamos relatar neste artigo a condução dos grupos de gestantes e puérperas no hospital, cujo objetivo era o de refletir acerca das representações sociais do papel de mãe, englobando as expectativas e frustrações existentes dentro deste papel, e de que forma buscamos fazer uso da Psicologia em intervenções que contribuíram para a ampliação das concepções acerca do papel de mãe.

\section{Metodologia}

Consistiu-se numa intervenção psicossocial que aconteceu no contexto de 15 encontros semanais com duração de aproximadamente 20 minutos, vivenciados pelas acadêmicas do curso de Psicologia da Universidade do Extremo Sul Catarinense (UNESC).

Sobre esse método de intervenção, Lopes e Nascimento (2015, p. 3) afirmam que "a intervenção psicossocial se configuraria em um processo de interação do sujeito com o meio ambiente com vistas à mudança no sentido de desenvolvimento de uma dada realidade".

As participantes foram gestantes e puérperas em internação, além de acompanhantes e familiares, no setor da maternidade de um hospital de ensino do extremo sul catarinense que se voluntariaram para as intervenções.

Inicialmente foi averiguada a rede de apoio das pacientes, como pais, cônjuges e amigos. Após esse período inicial, realizaram-se intervenções nos quartos com as mães e acompanhantes, em que foram abordadas as representações sociais do papel de mãe. Ao decorrer destas intervenções, as facilitadoras fizeram perguntas norteadoras como: "o que é uma boa mãe para você?”; “o que é uma mãe ruim?”; “o que é uma mãe mais ou menos?” enaltecendo uma reflexão acerca do tipo de mãe que esta se considerava, bem como os estereótipos associados ao assunto. As intervenções ocorreram semanalmente nos quartos coletivos das internas, localizados na ala da maternidade do hospital de ensino.

\section{Resultados e discussão}

Durante o período de observação foi verificada a rede de apoio das gestantes e puérperas da unidade da maternidade do hospital com o intuito de compreender a participação familiar e não familiar que elas recebiam durante a gravidez e pós-parto. É relevante ressaltar que muitas 
das participantes eram mães de primeira viagem e se apoiavam no que as outras relataram, pois julgavam não ter experiência necessária para opinar sobre o assunto.

Constatou-se necessária intervenção individual e formação de grupo para refletir acerca da representação social do papel de mãe e para verificar a expectativa da mãe em relação ao futuro do bebê. Em vista destes pontos elencados iniciaram-se as intervenções nos quartos a respeito da representação do papel de mãe, buscando identificar quais estereótipos surgiam sobre os tipos de papéis de mãe, sendo eles, o da boa mãe, da mãe ruim e da mãe mais ou menos. Todos os acompanhantes presentes no momento poderiam participar.

Buscou-se investigar se os achados em literatura relacionados à visão das mulheres acerca do papel de mãe eram verdadeiros, principalmente em relação ao que Azevedo (2017, p. 7) afirma no sentido de que “o 'ser mulher' está intrinsecamente relacionado ao 'ser mãe' e aos papéis que a sociedade exige serem cumpridos na maternidade", bem como se os "sentimentos" advindos da maternidade eram de fato vivenciados pelas gestantes.

Logo no início das intervenções, perceberam-se algumas falas prevalentes a respeito do que é considerado uma boa mãe. Nesse contexto, alguns tópicos como "dar educação", "fazer tudo pelo filho", "dar amor e carinho", "não deixar a criança 'largada"” e "amor incondicional" apareceram frequentemente, reafirmando o que é dito sobre a "dedicação e abnegação incondicional" (SILVA, 2013, p. 4), presumindo então que as mulheres devem ser mães perfeitas, descartando as ambivalências que podem surgir com a maternidade e que podem causar às mães muita angústia (AZEVEDO, 2017). Entende-se então, a partir disso, que nessas representações todas as mães são exemplares, que ser boa mãe surge como algo intrínseco às mulheres, algo inato.

Estes relatos sobre idealização excessivamente positiva do papel de boa mãe surgiram principalmente na fala de mulheres que não ingressaram ou mostraram interesse em cursar o ensino superior, sendo que as mulheres que frequentaram demonstram pensamento condizente com a realidade. O mesmo foi evidenciado em pesquisa de Ciscon-Evangelista et al. (2012). Conforme os autores as representações sociais a este respeito vão se modificando concomitantemente às transformações das práticas sociais e das informações que circulam nos ambientes sociais. Os dados de Ciscon-Evangelista et al. (2012) sugerem que o avanço feminino em termos de possibilidades de construção de uma carreira, não está relacionado apenas à complementação do sustento familiar, mas constitui importante elemento da realização pessoal e familiar, flexibilizando o papel de boa mãe, já que este deve coexistir com o papel profissional. 
Em contrapartida, as falas que prevaleceram a respeito do que é considerado uma mãe ruim, foram "dar para adoção", "fazer aborto", "não dar educação", “deixar a criança de lado", enquanto algumas participantes revelaram que não tinham como opinar por não ter nenhum exemplo na família ou simplesmente argumentaram que é "deixar de fazer o que a boa mãe faz". Tais dados foram igualmente encontrados por meio de entrevista com crianças realizada por Sampaio, Santos e Silva (2008). Em seus relatos, as crianças se apoiam na ideia de que as "mães boas" amam os seus filhos. O amor materno foi caracterizado através do carinho, da compreensão e da dedicação integral. Para as crianças, a mulher que se afasta desse modelo ideal de mãe é considerada uma mãe ruim, e não uma "não mãe". Portanto, nessa perspectiva não querer ser mãe já pode ser considerado como ser uma mãe ruim.

Não polarizando o papel de mãe, questionou-se também as perspectivas a respeito do papel de mãe "mais ou menos", ou seja, aquelas que não são totalmente "ruins" e não alcançam a idealização necessária para serem "boas”. Percebeu-se uma dificuldade de definição do que seria uma mãe "mais ou menos" estando sempre propensas ao lado negativo, pois as ações que não poderiam ser consideradas boas por elas - bater, dar limites, ir para o trabalho quando o filho está doente em casa - também não poderiam ser consideradas como "ruins" e sim necessárias.

Neste sentido, destacou-se a fala de uma mãe que se considerava uma mãe ruim no passado por ter atitudes negativas em relação à filha mais velha. Relatou que pela falta de paciência batia com frequência na criança por qualquer motivo, chegando a abandoná-la com a avó. Disse também perceber que a filha demonstra medo excessivo quando a mãe a chama. Demonstra culpa e arrependimento pelos comportamentos e vê no filho mais novo a oportunidade de fazer diferente. Apesar disso, ela é incentivada pelo marido e acha necessário recorrer à violência física como meio de punição e educação.

Diante deste relato, a segunda mãe presente no quarto contribuiu dando exemplo de como ela repreende a filha, salientando que conversar com a criança explicando o que ela fez de errado pode ser efetivo e como penalidade deixa a criança no "cantinho do pensamento" com tempo equivalente à idade da filha. Percebeu-se de acordo com esse posicionamento que a mesma não buscava julgar e sim dar uma sugestão, a partir de suas práticas sociais, para ampliar a perspectiva da mãe enquanto modelo parental em posição de respeito. Tal intervenção, não programada, nos fez perceber a importância dos grupos psicossociais de apoio. Conforme Ribeiro, Yamada e Silva (2005), o objetivo dos grupos psicossociais de apoio é oferecer uma 
escuta qualificada, favorecer a troca de experiências, intervir pontualmente em questões reflexivas, orientar e fornecer informações.

$\mathrm{Na}$ tentativa de fazê-las refletir utilizou-se exemplos de situações hipotéticas relatando a história de uma mãe que trabalhou o dia inteiro, chegou em casa cansada e não tem o suporte do marido na hora que a criança precisa de atenção. Nesse contexto, foi solicitado que avaliassem o tipo de mãe que esta seria se não conseguisse acordar no meio da noite se a criança chorasse. Novamente apareceu a divergência nas respostas. Ou a mãe foi considerada boa por estar dando sustento para a família e cuidando sem o auxílio do marido, ou ruim pois ao escolher ser mãe deve, obrigatoriamente, arcar com as responsabilidades da função.

Destacou-se a fala de uma participante cujo pensamento é de que "uma mãe mais ou menos, é mais ou menos em tudo e que, portanto, nunca conseguiria dar 100\% de si em nada". Diante disso, foram levantados questionamentos acerca do peso de ser mãe e alcançar este árduo ideal visto que "a maternidade não é algo ensinado ou discutido até a situação de gravidez e a mulher acaba por descobrir esta idealização e a impossibilidade de dar conta deste mito em sua vivência" (AZEVEDO, 2017, p. 10), o que pode gerar possíveis frustrações durante o desenvolvimento da criança e seu processo de criação.

Percebeu-se também que a respeito do papel de pai, ao questioná-las, revelou-se secundário ao da mãe, ou seja, o pai só daria suporte à criança quando a mãe não se encontrava. Durante os relatos, houve um número significativo de mães cujos filhos eram de pais diferentes. Nesses casos, constatou-se que poucos pais participavam financeiramente e/ou afetivamente da vida da criança e que as mães não buscavam os direitos desses filhos. O ofício de cuidadora ainda é considerado quase que exclusivo das mães, sendo que os pais assumem papéis de cuidadores secundários, que entram em cena apenas quando a mulher está indisponível, o que fortalece a percepção de que cuidar é função feminina (MARTINS; ABREU; FIGUEIREDO, 2014).

Por fim, a partir da intervenção psicossocial de representação social do papel de mãe assinala-se que apesar das mudanças ocorridas em prol das mulheres e de sua liberdade de escolha, o papel materno permaneceu almejado, porém imposto culturalmente pela sociedade. Buscou-se então a tentativa de desconstrução da idealização de polarização do papel de mãe, como boa ou ruim, destacando que é possível ser uma mãe "mais ou menos". No entanto, ficou evidente a dificuldade de combater séculos da popularização de um pensamento já enraizado no cerne coletivo. Com base nisso, levantamos alguns questionamentos para futuras pesquisas, 
no sentido de identidade social, papéis primários ou secundários no cuidado aos filhos, perspectivas futuras tanto da mãe quanto da criança pela visão da mulher e a influência da escolaridade na visão sobre maternidade.

\section{Considerações finais}

As vivências proporcionadas pelo estágio possibilitaram uma melhor compreensão de como funciona a maternidade e também dos indivíduos que passam por ela.

Percebemos a relevância das intervenções psicológicas tendo em vista que este é um momento delicado na vida da mulher e que muitas vezes elas não possuem o auxílio necessário durante e após o nascimento de seu esperado filho.

Pelo contato estabelecido com muitas mães, constatamos falas significativas sobre as representações sociais do papel de mãe e suas implicações futuras. Foi evidente que o ser mãe está intrinsecamente associado ao papel social da mulher sendo a ela considerado inato o amor incondicional. Para muitas mulheres ser mãe é uma profissão, geralmente não demonstrando interesse por uma carreira profissional. O homem, por sua vez, tem pouca atuação na criação do filho o que é reflexo da sociedade em que vivemos, devido ao fato de ser culturalmente ensinado o dever de provedor de sua família, enquanto a mulher atua como cuidadora.

Percebemos também que as falas que surgiram provinham de crenças profundamente consolidadas em nossa sociedade, e, portanto difíceis de serem alteradas. Como exemplo disso, quando as puérperas eram questionadas a respeito do seu papel, em diversas ocasiões suas acompanhantes, em sua maioria mulheres, ofereceram opiniões acerca do assunto, ditando a maneira como acreditavam que uma mãe deveria ser e isso acabou influenciando as puérperas a responderem de acordo com a opinião das mesmas. Curiosamente, notamos que as opiniões se repetiam frequentemente. Compreendemos então que não há "inovação" quanto ao papel materno, e que ele é regido por normas culturais que toda mãe "tem que" se adequar para ser considerada uma boa mãe.

Outro fator importante seria a falta de aceitação por parte tanto das mulheres quanto das pessoas que fazem parte do convívio das mesmas a respeito do cansaço que as mães sentem no dia-a-dia, de modo a desconsiderar seus limites físicos e emocionais.

Por fim, acreditamos que o estereótipo de mãe perfeita ainda seja o mais almejado pela grande maioria das mulheres que participaram, o que por sua vez pode desencadear processos 
ansiosos, já que conseguir alcançar esse ideal ancorado na nossa sociedade é, muitas vezes, inviável. Assim, é evidente a necessidade de futuras intervenções para que haja um maior entendimento a respeito deste tema que ainda é considerado periférico e um tabu na sociedade contemporânea.

\section{Referências}

AZEVEDO, Kátia Rosa; ARRAIS, Alessandra da Rocha. O mito da mãe exclusiva e seu impacto na depressão pós-parto. Psicologia: reflexão e crítica, v. 19, n. 2, p. 269-276, 2006. Disponível em: <http://www.scielo.br/pdf/prc/v19n2/a13v19n2>. Acesso em: 08 set. 2017.

AZEVEDO, Rhuama Ayube de. "Amo meu filho, mas odeio ser mãe": Reflexões sobre a ambivalência na maternidade contemporânea. 2017. 33 f. Monografia (Especialização) - Curso de Especialização em Psicologia, ênfase em Infância e Família: avaliação, prevenção e intervenção, Instituto de Psicologia, Universidade Federal do Rio Grande do Sul, Porto Alegre, 2017. Disponível em: <http://www.lume.ufrgs.br/bitstream/handle/10183/163940/001025591.pdf?sequence=1>. Acesso em: 07 set. 2017.

CISCON-EVANGELISTA, Mariane Ranzani et al. Pós-Graduação, formação profissional e postergação da constituição de família própria: um estudo com estudantes de mestrado e doutorado. Psicologia e Saber Social, Rio de Janeiro, v. 1, n. 2, p. 265-277, jul. 2012. Disponível em: <http://www.e-publicacoes.uerj.br/index.php/psi-sabersocial/article/view/4908/3631>. Acesso em: 03 out. 2017.

COZER, Patrícia Martins. Maria Monforte: perspectivas feministas e estereotipia. 2013. 70 f. Dissertação (Mestrado) - Curso de Estudos Feministas, Faculdade de Letras, Universidade de Coimbra, Coimbra, 2013. Disponível em: <https://estudogeral.sib.uc.pt/bitstream/10316/35841/1/Maria Monforte perspectivas feministas.pdf>. Acesso em: 01 set. 2017.

FOLINO, Cristiane da Silva Geraldo. Sobre dores e amores: caminhos da tristeza materna na elaboração psíquica da parentalidade. 2014. 212 f. Tese (Doutorado) - Curso de Psicologia Escolar e do Desenvolvimento Humano, Instituto de Psicologia, Universidade de São Paulo, São Paulo, 2014. Disponível em: <http://www.teses.usp.br/teses/disponiveis/47/47131/tde-02102014161452/publico/folino_corrigida.pdf>. Acesso em: 29 ago. 2017.

KOELZER, Larissa Papaleo et al. O "olhar preconceituoso": Representações sociais sobre fotografias nas redes sociais. Estudos e Pesquisas em Psicologia, Rio de Janeiro, v. 16, n. 2, p. 431-449, maio. 2016. Disponível em: <http://www.epublicacoes.uerj.br/index.php/revispsi/article/view/29169/20611>. Acesso em: 08 set. 2017.

LEAL, Cláudia Luiz. Maternidade distanciada: vivências de mães sobre o ajuste entre maternidade e profissão, da gestação ao retorno ao trabalho. 2013. 51 f. Monografia (Especialização) - Curso de Especialização em Psicologia - Ênfase em Infância e Família, Instituto de Psicologia, Universidade Federal do Rio Grande do Sul, Porto Alegre, 2013. Disponível em: <https://www.lume.ufrgs.br/bitstream/handle/10183/70909/000877983.pdf?sequence=1>. Acesso em: 07 set. 2017. 
LOPES, Leidiane Pereira; NASCIMENTO, Adriano Roberto Afonso do. O que faz uma psicologia social? Intervenção na psicologia social brasileira. Psicologia \& Sociedade, [s.l.], v. 28, n. 1, p. 14-25, abr. 2015. Disponível em: <http://www.scielo.br/pdf/psoc/2015nahead/1807-0310-psoc2015aop002.pdf>. Acesso em: 9 set. 2017.

MARTINS, Cristina Araújo; ABREU, Wilson Jorge Correia Pinto de; FIGUEIREDO, Maria do Céu Aguiar Barbieri de. Tornar-se pai e mãe: um papel socialmente construído. Revista de Enfermagem Referência, [s.l.], v. 4, n. 2, p. 121-131, jun. 2014. Disponível em: <http://www.redalyc.org/html/3882/388239972016/>. Acesso em: 07 set. 2017.

RIBEIRO, Sandra Fogaça Rosa; YAMADA, Midori Otake; SILVA, Cleonice da. Grupo de acompanhantes de pacientes com implante coclear: uma ação interdisciplinar da psicologia e do serviço social. Revista da Spagesp: Sociedade de Psicoterapias Analíticas Grupais do Estado de São Paulo, Ribeirão Preto, v. 6, n. 1, p.48-56, jan. 2005. Disponível em: <http://pepsic.bvsalud.org/pdf/rspagesp/v6n1/v6n1a07.pdf>. Acesso em: 08 set. 2017.

SAMPAIO, Juliana; SANTOS, Maria de Fátima de Souza; SILVA, Maria Rejane Ferreira da. A representação social da maternidade de crianças em idade escolar. Psicol. cienc. prof., Brasília, v. 28, n. 1, p. 174-185, 2008. Disponível em: <http://pepsic.bvsalud.org/pdf/pcp/v28n1/v28n1a13.pdf >. Acesso em: 12 nov. 2018.

SCHULTE, Andreia de Almeida. Maternidade contemporânea como sofrimento social em blogs brasileiros. 2016. 122 f. Dissertação (Mestrado) - Curso de Psicologia, Pontifícia Universidade Católica de Campinas, Campinas, 2016. Disponível em: <http://tede.bibliotecadigital.puccampinas.edu.br:8080/jspui/handle/tede/892>. Acesso em: 07 set. 2017.

SILVA, Tânia Maria Gomes da. Representações e vivências da maternidade nas camadas populares. In: SIMPÓSIO NACIONAL DE HISTÓRIA, 27., 2013, Natal. Anais... . Natal: Anpuh, 2013. p. 1-13. Disponível em: <http://snh2013.anpuh.org/resources/anais/27/1364813290_ARQUIVO_materniade,generoefeminism o.pdf>. Acesso em: 05 set. 2017.

TOURINHO, Julia. A mãe perfeita: idealização e realidade. IGT na Rede, Brasília, v. 3, n. 5, p.1-33, ago. 2006. Disponível em: <http://www.igt.psc.br/revistas/seer/ojs/viewarticle.php?id=24>. Acesso em: 17 set. 2017.

TRAVASSOS-RODRIGUEZ, Fernanda; FERES-CARNEIRO, Terezinha. Maternidade tardia e ambivalência: algumas reflexões. Tempo psicanalítico, Rio de Janeiro, v. 45, n. 1, p. 111-121, jun. 2013. Disponível em: < http://pepsic.bvsalud.org/pdf/tpsi/v45n1/v45n1a08.pdf >. Acesso em: 12 set. 2017.

\section{Como citar este artigo (Formato ABNT):}

ESTRELA, Jadne Meder; MACHADO, Maiara da Silva; CASTRO, Amanda. O "Ser Mãe": Representações Sociais do Papel Materno de Gestantes e Puérperas. Id on Line Rev.Mult. Psic., 2018, vol.12, n.42, Supl. 1, p. 569-578. ISSN: 1981-1179.

Recebido: 12/11/2018;

Aceito: $15 / 11 / 2018$ 